\title{
Medicated Nail Lacquer Dosage Form
}

National Cancer Institute

\section{Source}

National Cancer Institute. Medicated Nail Lacquer Dosage Form. NCI Thesaurus. Code C149650.

Liquid preparation to be applied to the nails to form a lacquer by evaporation of the volatile solvent. 